\title{
A study on risk factors, maternal and foetal outcome in cases of preeclampsia and eclampsia at a tertiary care hospital of South India
}

\author{
Bandaru Sailaja, Vijayalakshmi Cooly*, Bhuvaneswari Salicheemala, Surayapalem Salaija
}

Department of Obstetrics and Gynecology, Narayana Medical College, Nellore, Andhra Pradesh, India

Received: 20 October 2017

Accepted: 17 November 2017

\section{*Correspondence:}

Dr. Vijayalakshmi Cooly,

E-mail: sujatha2481@gmail.com

Copyright: (C) the author(s), publisher and licensee Medip Academy. This is an open-access article distributed under the terms of the Creative Commons Attribution Non-Commercial License, which permits unrestricted non-commercial use, distribution, and reproduction in any medium, provided the original work is properly cited.

\begin{abstract}
Background: Hypertension in pregnancy remains still a major health issue for women and their descendants throughout the world but remains a major issue in developing countries rather than developed countries. Eclampsia accounts for $24 \%$ of maternal deaths during pregnancy in India according to FOGSI study in India. Changing trends in pregnancy globally with increased maternal age of conception, assisted reproductive technologies has contributed a significant impact in the risk factors for PE and eclampsia. The present study was aimed to investigate and determine the related risk factors in cases of PE and eclampsia. The maternal and foetal outcomes with major complications of the women with PE and eclampsia were also studied.

Methods: A prospective cross sectional study for a period of two years was conducted at a tertiary care hospital among antenatal cases and all cases of PIH were recorded and studied. Cases were managed as per the existing obstetric protocol after clinical examination and investigations. Detailed socio demographic data and history of risk factors were collected and entered into Microsoft excel sheet and analyzed. Maternal and foetal outcome were noted in the cases of the study.

Results: The incidence of PE and eclampsia in the study was $43.3 \%$ and $10.8 \%, 25-35$ years age group being the most common. PE and eclampsia was associated with BMI $>30$, parous women with previous history of PE, diabetes mellitus and more in unregistered cases. PE and eclampsia were more in Illiterates and socio economic class $2 \& 3$. The incidence of maternal complications was $32.99 \%$ with premature labour being the common and in case of foetal complications prematurity was the commonest with 16 cases. The maternal mortality was very less with only $4.64 \%$ in the study.

Conclusions: Pregnancy induced hypertension with PE and eclampsia still remains a major problem in developed countries. Good antenatal care with increased awareness and increased antenatal visits may help in reducing the incidence and maternal and foetal complications. Increased incidence among illiterates and low socio economic status group provides the target group to be directed against any medical measures and national health programmes.
\end{abstract}

Keywords: Eclampsia, Preeclampsia, Pregnancy induced hypertension, Prematurity

\section{INTRODUCTION}

Hypertension in pregnancy remains still a major health issue for women and their descendants throughout the world but remains a major issue in developing countries rather than developed countries. Globally preeclampsia [PE] and eclampsia are responsible for approximately
$14 \%$ of maternal deaths with variable incidences in developed and developing countries. ${ }^{1}$ Eclampsia accounts for $24 \%$ of maternal deaths during pregnancy in India according to FOGSI study in India. ${ }^{2}$ Gestational hypertension affects $5-10 \%$ of pregnancies, but is associated with fewer and less severe complications. Eclampsia is defined as the new onset of generalized 
tonic clonic seizure in women with severe preeclampsia. $\mathrm{PE}$ is associated with cardio vascular complications in later life and also in their offspring. Most of the previous epidemiological studies focused and examined the risk factors of gestational hypertension and PE with useful information with respect to the etiological mechanism and prediction and management of hypertensive disorders of pregnancy. ${ }^{3}$ Changing trends in pregnancy globally with increased maternal age of conception, assisted reproductive technologies has contributed a significant impact in the risk factors for PE and eclampsia. Most of the studies focused on risk factors like age etc and different diagnostic criteria for PE and eclampsia. PE and eclampsia are considered important in early diagnosis and management as both are associated with serious maternal and foetal outcomes and complications during pregnancy and in later life of mother and offspring. ${ }^{4}$ Most of the studies have focused aiming at identification of maternal death risk factors but the diagnostic criteria were variable. However, the findings in different studies were inconsistent which may be attributable to different diagnostic criteria, heterogeneity of population etc. Proper antenatal care still remains an important part in prevention of PE and eclampsia with associated mortality and complications. Hence estimating each woman's individualized risk allows proper antenatal surveillance to be directed against those having a risk of PE and eclampsia. Hence always there is a need to develop an integrated model for estimation of individual risk factors for development of $\mathrm{PE}$ on the basis of various parameters. ${ }^{5}$

The present study was aimed to investigate and determine the related risk factors in cases of PE and eclampsia. The maternal and foetal outcomes with major complications of the women with PE and eclampsia were also studied.

\section{METHODS}

The present prospective cross sectional study was conducted at a tertiary care hospital for a period of two years from March 2015 to February 2017 by the Department of Gynecology and Obstetrics. All the antenatal patients attending the obstetrics OPD for regular visits were included in the study. All the cases that were diagnosed with preeclampsia and eclampsia during the visits or during the stay in the hospital were admitted. The socio demographic data (Age, weight, height etc) of all the antenatal patients were recorded by personal interviewing and thoroughly examined clinically for gestational age and blood pressure recordings were noted regularly during all the visits. Body mass index was calculated at the first antenatal booking visit. All the data was entered in a separate proforma sheet and noted. Cases with past history of seizures and known convulsive history were excluded from the study. Cases with ante partum eclampsia were included and intrapartum, postpartum eclampsia were excluded. Registered cases were defined as cases with a minimum of 4 regular antenatal visits to a health center or by a health worker as per WHO guidelines. All the cases of preeclampsia and eclampsia were defined and diagnosed as per the Guidelines of WHO. All the cases of eclampsia and preeclampsia were admitted in the hospital ward and followed till the delivery and maternal, foetal outcome was noted. Maternal outcome was registered as normal delivery, LSCS, complications and death. Foetal outcomes were measured as still birth, low birth weight, complications and good. The study was approved by the Institutional ethical committee and all the ethical guidelines were followed during the study period.

\section{Case definitions}

- Preeclampsia: Preeclampsia is defined as high blood pressure of $140 / 90 \mathrm{~mm}$ of $\mathrm{Hg}$ or more along with proteinuria $0.3 \mathrm{~g} / 24 \mathrm{~h}$ or any derangement in platelet count, liver enzymes or renal function tests after 22 weeks of gestation.

- Eclampsia: Presence of convulsions that cannot be attributed to other causes in a woman with preeclampsia.

BMI of the case was calculated as per the WHO guidelines and Categorized as Normal range: 18.5-24.99; Overweight: $\geq 25$; Pre-obese:25-29.99 and Obese: $\geq 30{ }^{6}$

\section{RESULTS}

The present study which was conducted at a tertiary care hospital for a period of two years recorded 388 cases of pregnancy induced hypertension among 18478 cases who visited for antenatal checkups during the study period. Out of 388 recorded cases, 178 were categorized as mild PIH (45.9\%), 168 as preeclampsia $(43.3 \%)$ and 42 as eclampsia $(10.8 \%)$.

Of the 388 cases, maximum cases were in the age group of 26-35 years $(166 / 388,52.78 \%)$ followed in order by $>35$ years $(32.47 \%)$ and $15-25$ years $(24.74 \%)$. The mean age of the patients in the study was $28 \pm 4.3$ years. In our study, cases with mild PIH were maximum in 26-35 years $(53 \%)$, preeclampsia in $>35$ years age group $(46 \%)$ and eclampsia in 26-35 years group (20.5\%). In our study, $51.03 \%$ of cases were illiterate, and maximum number of illiterate cases were observed in mild PIH group (49\%), $45.3 \%$ of cases with preeclampsia were educated up to high school and no significant difference was observed among the graduates in categorization. With regards to socio economic status of cases in the study, as per Kuppuswamy's scale, $32.99 \%$ were placed in socio economic class-2 followed in order by class-4 $(28.87 \%)$, class-3 $(27.84 \%)$, class-1 $(6.7 \%)$ and least in class-5 $(3.61 \%) .^{7}$ Out of 42 cases of eclampsia there was no much difference in the cases in class-3 \&4 but less number in class- 5 where only 4 cases were recognized. $73.2 \%$ of cases were house wives and $26.8 \%$ were employers working in different categories. Most of the cases of mild PIH, preeclampsia and eclampsia were observed in housewives rather than employers. $59.28 \%$ of 
cases were from joint family and the rest $40.72 \%$ from nuclear family. There was no significant observation and differences in the distribution of cases in the study with regard to type of family (Table 1).

Table 1: Socio demographic parameters of cases in the study.

\begin{tabular}{|c|c|c|c|c|c|c|c|}
\hline \multirow{2}{*}{ Maternal age (Years) } & \multirow{2}{*}{ Total } & \multicolumn{2}{|l|}{ Mild PIH } & \multicolumn{2}{|c|}{ Pre-eclampsia } & \multicolumn{2}{|c|}{ Eclampsia } \\
\hline & & Number & $\%$ & Number & $\%$ & Number & $\%$ \\
\hline $15-25$ years & 96 & 45 & 46.9 & 35 & 36.5 & 16 & 16.7 \\
\hline $26-35$ years & 166 & 88 & 53 & 44 & 26.5 & 34 & 20.5 \\
\hline$>35$ years & 126 & 44 & 35 & 58 & 46 & 24 & 19 \\
\hline Total & 388 & 178 & 45.9 & 168 & 43.3 & 42 & 10.8 \\
\hline \multicolumn{8}{|l|}{ Education $(\mathrm{n}=388)$} \\
\hline Illiterate & 198 & 97 & 49 & 86 & 43.4 & 15 & 7.6 \\
\hline High school & 150 & 67 & 44.7 & 68 & 45.3 & 15 & 10 \\
\hline Graduation & 40 & 14 & 35 & 14 & 35 & 12 & 30 \\
\hline \multicolumn{8}{|c|}{ Socio economic class $(n=388)$} \\
\hline Class 1 & 26 & 10 & 38.5 & 8 & 30.8 & 8 & 30.8 \\
\hline Class 2 & 128 & 67 & 52.3 & 52 & 40.6 & 9 & 7 \\
\hline Class 3 & 108 & 47 & 43.5 & 50 & 46.3 & 11 & 10.2 \\
\hline Class 4 & 112 & 48 & 42.9 & 54 & 48.2 & 10 & 8.9 \\
\hline Class 5 & 14 & 6 & 42.9 & 4 & 28.6 & 4 & 28.6 \\
\hline \multicolumn{8}{|l|}{ Occupation $(n=388)$} \\
\hline House wife & 284 & 124 & 43.7 & 130 & 45.8 & 30 & 10.6 \\
\hline Employer & 104 & 54 & 51.9 & 38 & 36.5 & 12 & 11.5 \\
\hline \multicolumn{8}{|l|}{ Type of family ( $n=388$ ) } \\
\hline Nuclear & 158 & 78 & 49.4 & 64 & 40.5 & 16 & 10.1 \\
\hline Joint family & 230 & 100 & 43.5 & 104 & 45.2 & 26 & 11.3 \\
\hline
\end{tabular}

Table 2: Risk factors of cases in the study.

\begin{tabular}{|c|c|c|c|c|}
\hline \multirow[t]{2}{*}{ Risk factors } & \multirow{2}{*}{$\begin{array}{l}\text { Total cases }(\mathrm{n}=\mathbf{3 8 8}) \\
(\%)\end{array}$} & $\begin{array}{l}\text { Mild PIH } \\
(\mathrm{n}=178)\end{array}$ & $\begin{array}{l}\text { Pre-eclampsia } \\
(\mathrm{n}=168)\end{array}$ & $\begin{array}{l}\text { Eclampsia } \\
(\mathrm{n}=42)\end{array}$ \\
\hline & & Number & Number & Number \\
\hline \multicolumn{5}{|l|}{ BMI [Body mass index] } \\
\hline$<18.5$ & $123(31.70)$ & 98 & 18 & 7 \\
\hline $18.5-24.9$ & $72(18.56)$ & 38 & 27 & 7 \\
\hline $25-29.9$ & $73(18.81)$ & 31 & 34 & 8 \\
\hline$>30$ & $120(30.93)$ & 11 & 89 & 20 \\
\hline \multicolumn{5}{|l|}{ Parity } \\
\hline Nulliparous & $138(35.57)$ & 102 & 22 & 14 \\
\hline Parous without PE & $140(36.08)$ & 70 & 54 & 16 \\
\hline Parous with previous PE & $120(30.93)$ & 16 & 92 & 12 \\
\hline \multicolumn{5}{|l|}{ Conception } \\
\hline Spontaneous & $322(83)$ & 150 & 138 & 34 \\
\hline Through ART & $66(17)$ & 28 & 30 & 8 \\
\hline \multicolumn{5}{|l|}{ Diabetes mellitus ( $n=42)$} \\
\hline Type I & $7(16.7)$ & 3 & 4 & 0 \\
\hline Type II & $15(35.7)$ & 17 & 6 & 2 \\
\hline Gestational & $10(23.8)$ & 4 & 4 & 2 \\
\hline \multicolumn{5}{|l|}{ Number of Babies } \\
\hline Singleton & 356 (91.75) & 160 & 156 & 40 \\
\hline Twin & $32(8.25)$ & 18 & 12 & 2 \\
\hline Registered & $264(68.04)$ & 120 & 120 & 24 \\
\hline Unregistered & $124(31.96)$ & 58 & 48 & 18 \\
\hline
\end{tabular}


Table 2 clearly demonstrates the risk factors associated with the cases in the study. $30.93 \%$ of cases in the study had BMI >30 with 89 cases of preeclampsia, 20 cases of eclampsia and 11 cases with mild PIH. $36.08 \%$ of cases were parous without any history of preeclampsia and $35.57 \%$ were nulliparous and $30.93 \%$ cases with history of preeclampsia. Out of 120 cases with previous history of preeclampsia 92 cases developed preeclampsia,12 cases with eclampsia and 16 cases with mild PIH. $83 \%$ of cases in the study conceived by natural methods, $17 \%$ of cases conceived by assisted reproductive technology. 42 cases in $388(10.8 \%)$ were with diabetes mellitus in the study with 15 cases of type- II, 7 with type-I and 10 cases were identified as gestational diabetes mellitus. $68.04 \%$ of cases in the study were booked cases with minimum 4 antenatal visits and $31.96 \%$ gave no account of antenatal care in the pregnancy 24 cases of 264 cases developed eclampsia and 18 cases of unregistered cases. But 120 cases of registered developed preeclampsia and 48 of unregistered developed preeclampsia in the study. Statistical significance was associated with BMI, parity with previous history of Preeclampsia in the study. (' $p$ ' valve $<0.005)$.

Table 3: Maternal outcome among cases in the study.

\begin{tabular}{|ll|l|}
\hline Maternal outcome & Number & $\%$ \\
\hline Normal delivery & 174 & 44.85 \\
\hline Caesarean delivery & 68 & 17.53 \\
\hline Complications & 128 & 32.99 \\
\hline Preterm labour & 41 & \\
\hline Abruptio placentae & 14 & \\
\hline Post partum hemorrhage & 34 & \\
\hline HELLP syndrome & 11 & \\
\hline Renal failure & 12 & \\
\hline DIC & 16 & \\
\hline Death & 18 & 4.64 \\
\hline
\end{tabular}

Table 4: Foetal outcome among cases in the study.

\begin{tabular}{|lll|}
\hline Foetal outcome & Number & $\%$ \\
\hline Low birth weight & 54 & 16.88 \\
\hline Still birth & 24 & 7.5 \\
\hline Complications & 40 & 12.5 \\
\hline Prematurity & 16 & \\
\hline Birth asphyxia & 8 & \\
\hline IUGR & 8 & \\
\hline Intrauterine death & 4 & \\
\hline Neonatal death & 4 & \\
\hline Normal & 202 & 63.13 \\
\hline
\end{tabular}

Table 3 demonstrates the maternal outcome of cases in the study. $44.85 \%$ of cases had normal vaginal delivery, $17.53 \%$ had LSCS, most common reason being failure of induction and foetal distress. $32.99 \%$ of cases developed complications during the study of which 41 cases developed preterm labour, 34 cases with $\mathrm{PPH}, 16$ with DIC, abruption placentae (14), Renal failure (12) and
HELLP syndrome in 11 cases. The mortality was very less with 18 cases $(4.64 \%)$.

Foetal outcome in the study is explained in table-4. 320 deliveries $(82.47 \%)$ were conducted on 370 remaining cases after 18 deaths in the study.63.13\% of cases recorded normal outcome, $16.88 \%$ with low birth weight, $7.5 \%$ with still birth and $12,5 \%$ of cases developed complications. Prematurity was the commonest (16 cases) and birth asphyxia (8), IUGR (8), Intra uterine death (4) and neonatal death (4).

\section{DISCUSSION}

In the present study, there were 18478 admissions out of which 388 cases were diagnosed with pregnancy induced hypertension with an overall incidence of $2.1 \%$. The incidence of mild PIH in the study was $45.9 \%$, preeclampsia $43.3 \%$ and eclampsia $10.8 \%$. These findings of our study were on par with the findings of Duley et al and contrary to the findings of Shalini et al who reported the incidence of eclampsia as $14 \%$ and PIH as $8 \%$ in her study. ${ }^{8,9}$ The maximum cases in the present study were between 26-35 years with $52.78 \%$ which coincides with the findings of many studies globally but a study conducted by Bhattacharya $\mathrm{S}$ has found maximum cases in age group of 15-25 years, however the study group is always variable factor depends upon the region and not a constant feature. ${ }^{10}$ Most of the identified cases in the present group were illiterate, and placed in socio economic class 2 and 3 as per Kuppuswamy's classification. Illiteracy and low socio economic status are always associated with lack of adequate knowledge regarding antenatal care and importance of antenatal visits regarding maternal morbidity and complications. Most of the cases were house wives and from joint families. However, occupation and type of family has no proven influence on the pregnancy induce hypertension, preeclampsia and eclampsia. Few studies mention PE to be observed mostly in cases from joint families than single or nuclear family.

Risk factors: Most of the studies conducted earlier identified, extremes of maternal age, twin paternity, nulliparity, increased BMI, increased systolic and diastolic blood pressure during early pregnancy and presence of gestational diabetes are risk factors in development of PIH and eclampsia. In our study, the incidence of eclampsia and PE was observed maximally in cases with BMI $>30$ and mild PIH in cases with $\mathrm{BMI}<18.5$ which is an unusual feature in our study. The incidence of eclampsia and PE in our study was similar to the findings of Duckitt $\mathrm{K}$ in his study. ${ }^{11}$ In present study, the incidence of diabetes cases was $10.83 \%$, with $35.7 \%$ type-2 Diabetes and $16.7 \%$ with type-1. $23.8 \%$ of cases developed gestational diabetes mellitus. The incidence of PIH among the diabetics in the study was $57.14 \%$, PE was $33.34 \%$ and Eclampsia was $9.5 \%$. Ros et al. quoted that in diabetic women, high levels of plasma triglycerides cause endothelial cells to accumulate 
triglycerides leading to endothelial cell dysfunction that predisposes to develop high blood pressure. ${ }^{12}$ In the present study, $68.04 \%$ of cases were booked with adequate antenatal care and $31.96 \%$ were unregistered without antenatal care. The incidence of $\mathrm{PE}$ in unregistered cases was $38.70 \%$ and eclampsia was $14.51 \%$ which was comparable with the findings of Sudarsan et al and Tukur et al in their studies. ${ }^{13,14} 66$ cases in our study, were conceived by ART of which $12.12 \%$ developed eclampsia, $45.45 \%$ developed PE. Studies on this regard are very limited and could not be compared. Parity with previous history of $\mathrm{PE}$ is a significant risk factor as mentioned earlier in many studies, which was also observed in our study also with an incidence of $10 \%$ with eclampsia and $76.7 \%$ with preeclampsia. Findings of our study were coincident with the findings of Cincotta RB et al in his study. ${ }^{15}$

Maternal outcome: In the present study the incidence of normal delivery; LSCS was $44.85 \%$ and $17.53 \%$ which was almost similar to Minire An et al who reported normal delivery as $52 \%$ and LSCS as $21 \%$ in his study. ${ }^{16}$ The incidence of complications in our study was $33 \%$, the commonest being preterm labour affecting 41 out of 128 cases, (32\%) and followed by post partum hemorrhage (26.56\%), DIC (12.5\%), abruptio placentae (10.93\%) and renal failure, HELLP syndrome $(9.3 \%)$. Out of 34 cases that developed PPH 12 cases required blood transfusion. Similar findings were reported by Naseer D et al but contrary to Al-Mulhim AA et al who reported abruption of placentae as the most common and HELLP syndrome in $18 \%$ of cases in his study. ${ }^{17,18}$ The incidence of maternal mortality in our study was $4.64 \%$ which is very less compared to the findings in the studies of Singhal $\mathrm{S}$ et al in their study who reported the incidence as $8.7 \% .^{19}$

Foetal outcome: Prematurity was the commonest foetal complication in our study with $40 \%$ followed by birth asphyxia, IUGR (20\%) and Intra uterine death in $10 \%$. These findings of our study were similar to many studies earlier but contrary to the findings of Kapoor et al who reported birth asphyxia as the most common complication in his study. ${ }^{20}$ Foetal complications were more commonly observed in cases of severe eclampsia and preeclampsia than in cases with mild $\mathrm{PIH}$.

\section{CONCLUSION}

To conclude, pregnancy induced hypertension with PE and eclampsia still remains a major problem in developed countries. Good antenatal care with increased awareness and increased antenatal visits may help in reducing the incidence and maternal and foetal complications. Increased incidence among illiterates and low socio economic status group provides the target group to be directed against any medical measures and national health programmes. Identifying the cases at an early period by regular recording of blood pressure at every visit, history of previous PE and diabetes mellitus always helps in identification of cases early and proper institutional management reduces the maternal and foetal deaths due to preeclampsia and eclampsia.

Funding: No funding sources

Conflict of interest: None declared

Ethical approval: The study was approved by the Institutional Ethics Committee

\section{REFERENCES}

1. Cecil RL, Goldman L, Schafer AI. Goldman's Cecil medicine (24th ed.). Philadelphia, PA: Elsevier Saunders; 2012.

2. Konar H, Chakraborty AB. Maternal Mortality: A FOGSI Study (Based on Institutional Data). J Obstet Gynecol India. 2013; 63(2):88-95.

3. Khan KS, Wojdyla D, Say L, Gülmezoglu AM, VanLook PF. WHO analysis of causes of maternal death: a systematic review. Lancet. 2006;367(9516):106674.

4. Jye CJ. Challenges of obstetrician in the management of severe preeclampsia. Obstet Gynaecol Today. 2009;16(8):348-51.

5. Carty DM, Delles C, Dominiczak AF. Preeclampsia and future maternal health. $\mathrm{J}$ Hypertens. 2010;28:1349-55.

6. WHO expert consultation. Appropriate Body mass index for Asian populations and its implications for policy and intervention strategies. Lancet. 2004:157163.

7. Singh T, Sharma S, Nagesh S.Socio-economic status scales updated for 2017. Int J Res Med Sci. 2017;5:3264-7.

8. Duley L Global impact of preeclampsia and eclampsia. Semin perinatal. 2009;33(3):130-7.

9. Shalini K, Ruchi Sehgal: Management of obstetric hypertensive crisis. Obstet Gynaecol Today. 2007; 12:450-2.

10. Mohan BS. Pregnancy induced hypertension and prior trophoblastic exposure. J Obstet Gynecol India. 2004;54(6):568-70.

11. Duckitt K, Harrington D. Risk factors for preeclampsia at antenatal booking: systematic review of controlled studies. BMJ. 2005;30(749):565.

12. Ros HS, Cnattingius S, Lipworth L. Comparison of risk factors for preeclampsia and gestational hypertension in a population-based cohort study. Am J Epidemiol. 1998;147:1062-70.

13. Saha S. Comparative study on the efficacy of magnesium sulphate and diazepam in the management of eclampsia in a peripheral rural medical college (Across over study of 440 cases). J Obstet Gynecol India. 2002;52(3):6972.

14. Tukur J, Umar BA, Rabi'u A. Pattern of eclampsia in a tertiary health facility situated in a semi-rural town inNorthern Nigeria. Ann Afr Med. 2007;6(4):164-7.

15. Cincotta RB, Brennecke SP. Family history of preeclampsia as a predictor for pre-eclampsia in primigravidas. Int J Gynecol Obstet. 1998;60:23-7. 
16. Minire A, Mirton M, Imri V, Lauren M, Aferdita M.Maternal complications of preeclampsia. Med Arch. 2013;67(5):339-41.

17. Naseer D, Ataullah K, Nudrat E. Perinatal and maternal outcome of eclamptic patients admitted in Nishtar Hospital, Multan. J Coll Physician Surg Pak. 2000;10:261-4.

18. Al-Mulhim AA, Abu-Heija A, AlJamma F, El-Harith el-HA. Preeclampsia: maternal risk factors and perinatal outcome. Fetal Diagn Ther. 2003;18(4):275-80.

19. Singhal S, Deepika, Anshu, Nanda S. Maternal and perinatal outcome in severe pre-eclampsia and eclampsia. South Asian Federation Obstet Gynecol. 2009;1(3):25-8.

20. Kapoor M, Agrawal N, Jain PK, Sethi RS, Gupta U, Goyal L. Perinatal outcome in hypertensive disorders in pregnancy. J Obstet Gynecol India. 1991;41:1625.

Cite this article as: Sailaja B, Cooly V, Salicheemala B, Salaija S. A study on risk factors, maternal and foetal outcome in cases of preeclampsia and eclampsia at a tertiary care hospital of South India. Int J Reprod Contracept Obstet Gynecol 2018;7:266-71. 